\title{
Programa nacional garante qualidade do sal consumido no País \\ $\mathrm{N}$ ational program assures quality to salt consumed in the country \\ Agência Nacional de Vigilância Sanitária - Anvisa*
}

Terra plana, alta temperatura, pouca chuva e muito vento. Essas são as características geográficas do litoral nordestino que fizeram do Rio Grande do Norte o maior produtor de sal do País, região onde as montanhas de sal estão tornando-se ponto turístico e concorrendo com as belas praias do local. Grande parte do sal que chega à mesa da população no País é produzido no Estado. E para garantir a qualidade desse produto e melhorar o monitoramento da produção, a Subcoordenação de Vigilância Sanitária do Rio Grande do Norte (Suvisa) integrou o "Programa Nacional de Inspeção Sanitária nos Estabelecimentos Beneficiadores de Sal Destinado ao Consumo Humano", coordenado pela Anvisa entre os anos de 2000 e 2003.

O programa, de iniciativa da Agência, teve como objetivo garantir a adição de iodo ao sal oferecido aos brasileiros, em padrões definidos pela legislação sanitária. Outro ponto importante foi a verificação do cumprimento das Boas Práticas de Fabricação (BPF) na produção. Um sal adequado para a saúde deve conter entre 20 e 60 miligramas de iodo para cada quilograma de sal.

Assim como a Suvisa, 11 vigilâncias estaduais fizeram parte do monitoramento nacional do sal. A realização do programa deveu-se à constatação, por oito estados, de que $27 \%$ das amostras coletadas, em 1999 , apresentaram teor de iodo abaixo do permitido. A primeira ação que permitiu a execução do programa foi a qualificação de 26 fiscais de dez estados e seis do órgão federal com o "Curso de Capacitação Técnica em Inspeção Sanitária em Indústrias Beneficiadoras de Sal", realizado pela Agência, em fevereiro de 2000. Outra iniciativa importante foi o convênio estabelecido entre a Anvisa e o Serviço Nacional de Aprendizagem Industrial (Senai), que possibilitou a várias indústrias aplicarem as BPF.

O subcoordenador da Suvisa, Marcos Sérgio Guerra, afirma que o treinamento oferecido pela Agência deu segurança aos fiscais: "A equipe agora pode orientar melhor os produtores. Depois de cada inspeção explicamos o porquê da correção dos erros encontrados e da adição do iodo na quantidade indicada pela legislação". Guerra destaca que, em virtude do convê- nio, das 36 indústrias no estado, 14 já aplicam as BPF e 16 estão em fase de desenvolvimento.

Na primeira etapa do programa, as vigilâncias estaduais inspecionaram todas as indústrias salineiras de suas regiões. Ao todo, existem no Brasil 86 empresas, sendo que $42 \%$ se concentram no Rio Grande do Norte. Para aquelas que não conseguiram atender de imediato aos requisitos de BPF, foi concedido um prazo de 180 dias. As mudanças exigiram alguns investimentos por parte das indústrias salineiras, como reestruturação do espaço físico e manutenção de equipamentos.

A gerente da Anvisa responsável pelo programa, Ana Virgínia de Almeida Figueiredo, explica que esse prazo foi prorrogado por igual período porque foi constatado que, apesar do esforço, as indústrias não estavam conseguindo atender às exigências no tempo estipulado: "No início do monitoramento existiam 198 estabelecimentos cadastrados no banco de dados. Destes restaram apenas 86 , os outros estavam desativados ou desistiram de investir no setor por não conseguirem se adequar à legislação". Os prazos, no entanto, não valeram para irregularidades de adição de iodo, que deveriam ser sanadas no término do prazo inicial, assim que fosse detectado algum problema. A fase seguinte foi a reinspeção de todas as empresas.

Depois de inspecionadas, os resultados apareceram. Nos dois primeiros anos, a variação do percentual de laudos insatisfatórios quanto ao teor de iodo não foi tão significativa, já que as empresas estavam ajustando-se às exigências. Em 2000, detectou-se 27\% - o mesmo do ano anterior -, e, em 2001, chegou a $29 \%$. Mas nos anos seguintes foram verificadas reduções de $11 \%$ e $6 \%$, para 2002 e 2003 , respectivamente. $\mathrm{O}$ êxito conquistado em âmbito nacional foi constatado no Rio Grande do Norte. No ano passado, das 111 amostras analisadas, nove foram reprovadas.

\section{RESPO N SABILIDADE}

A produção de sal em Macau, localizada a $178 \mathrm{~km}$ de Natal, RN, constitui a base da economia da cidade e 
emprega a maioria dos trabalhadores da região. $\mathrm{O}$ macauense Arildo de Mendonça Paulo é controlador do teor de iodo da quarta maior empresa produtora de sal para consumo humano do Brasil e exerce uma função diretamente ligada à qualidade da saúde. Mendonça sabe da importância da adição do iodo e por isso tem consciência da responsabilidade do seu trabalho: "Com isso, previno problemas de saúde de milhares de brasileiros que comem alimentos com o sal produzido pela nossa equipe".

O secretário-executivo da Associação Brasileira de Extratores e Refinadores de Sal (Abersal), Afrânio Manhães Barreto, que trabalha na entidade há 34 anos, afirma que "é extraordinário o progresso que o programa da Anvisa proporcionou ao País. Criou-se uma interação entre setor produtivo e governo. Agora todos trabalham juntos para beneficiar a saúde da população". A Abersal reúne as nove maiores indústrias salineiras do País, responsáveis por $80 \%$ do sal comercializado no Brasil.

Anualmente, os brasileiros consomem aproximadamente um milhão de toneladas de sal, que hoje é instrumento de prevenção a uma das mais visíveis doenças derivadas da falta de iodo: o bócio. O monitoramento da qualidade do sal está diretamente ligado ao controle dessa doença e de outros Distúrbios por Deficiências de Iodo (DDI), males causados pela ausência de iodo no organismo que atingem pessoas de todas as faixas etárias. A escolha do sal como o ingrediente que leva ao consumidor o iodo se deve, entre outros fatores, à sua ingestão, em pequenas quantidades diárias, por milhões de brasileiros. Além disso, é o alimento no qual o nutriente pode ser adicionado por meio de tecnologia simples e de baixo custo.

O risco da ausência de iodo na dieta alimentar começa na gestação. Durante a gravidez, a carência pode causar abortos, má formação do feto, nascimento prematuro, entre outros. Se a deficiência ocorrer nas primeiras fases do desenvolvimento, a criança pode ter funções psicomotoras comprometidas e redução da capacidade de concentração e aprendizado. Já na idade adulta, a deficiência de iodo provoca formação do bócio,conhecido popularmente como "papo".

\section{LEVANTAMENTO}

Desde que foi determinada a obrigatoriedade da adição de iodo no sal, em 1953, o Ministério da Saúde realizou quatro pesquisas para quantificar a existência do bócio no Brasil com alunos de 6 a 14 anos de escolas públicas de várias regiões. A primeira, feita em 1955 , detectou que $20,7 \%$ das crianças examinadas apresentaram a doença. Dezenove anos depois, outra pesquisa constatou um índice de $14,1 \%$.

Diante desses resultados, em 1984, foram escolhidos 13 municípios dos estados de Minas Gerais, Goiás, Maranhão, Pará e Tocantins, chamados de municípios-sentinela, para monitorar incidência da doença nes- sas regiões. $\mathrm{O}$ estudo mostrou que a concentração variou de $16,4 \%$ a $39,9 \%$. O último levantamento, feito em 1995, com 17 cidades de sete estados, mostrou que 1,3\% das 179 mil crianças estudadas apresentava bócio. A diminuição da incidência dessa doença em várias regiões do País indica que o controle dos DDI tem melhorado a cada ano.

Em 2000, o projeto Thyromobil do Conselho Internacional para Controle de Doenças Causadas pela Deficiência de Iodo, criado para avaliar as conseqüências de carência de iodo em países europeus, também proporcionou grandes avanços para o controle sanitário da produção de sal no País. Trazido com apoio do Ministério da Saúde, o projeto selecionou 17 municípios de seis estados para verificar a predominância de bócio nessas regiões. Durante três meses, a equipe responsável pela execução do projeto no Brasil percorreu as localidades demarcadas, desenvolvendo estudos com 1.977 alunos de seis a 12 anos.

A metodologia do projeto envolveu a realização de exames para verificar o tamanho da tireóide, análise da urina de $65 \%$ do público estudado, coleta de amostras do sal exposto nos comércios locais e na casa das crianças estudadas. Ao todo, foram colhidas 1.325 amostras de sal e 1.013 de urina. Os resultados constataram excesso de iodo na urina e prevalência de bócio em $1,4 \%$ e mostraram que o percentual encontrado no Brasil está abaixo do limite máximo de 5\% estabelecido pela Organização Mundial de Saúde.

O controle sanitário do sal tem sido aperfeiçoado constantemente. Tanto que o teor do iodo pôde ser reduzido. A consultora técnica da Coordenação de Política de Alimentação e Nutrição do Ministério da Saúde, Gracy Heijblom, afirma que a evolução dos resultados da pesquisa foi significativa e colaborou para essa diminuição, mas o monitoramento deve sempre existir, até mesmo para adequações como estas. Para ela, "o controle sanitário do sal, aliado a campanhas de conscientização do setor produtivo, foi essencial para a redução do bócio endêmico no Brasil”".

Para dar continuidade às ações, a Anvisa integra a Comissão Interinstitucional para Controle dos DDI, formada em outubro de 1999. A comissão é composta por representantes de diferentes segmentos da sociedade e busca prevenir a proliferação dos distúrbios.

A Suvisa comemora os resultados do programa no Rio Grande do Norte. "É uma satisfação saber que todas as ações surtiram efeitos positivos. A integração entre produtores e vigilância sanitária foi fundamental", atesta o subcoordenador do estado.

O programa nacional do sal foi finalizado, mas o controle da produção será mantido pelas vigilâncias estaduais e agora faz parte do Termo de Ajuste e Metas. Assim, 100\% das indústrias salineiras devem ser inspecionadas, anualmente, pelos estados. 